\title{
Decontamination of dental implant surfaces by means of photodynamic therapy
}

\author{
Juliana Marotti • Pedro Tortamano • Silvana Cai • \\ Martha Simões Ribeiro • \\ João Eduardo Miranda Franco • \\ Tomie Toyota de Campos \\ Received: 17 October 2011 / Accepted: 22 June 2012 / Published online: 12 July 2012 \\ (C) The Author(s) 2012. This article is published with open access at Springerlink.com
}

\begin{abstract}
Several implant surface debridement methods have been reported for the treatment of peri-implantitis, however, some of them can damage the implant surface or promote bacterial resistance. Photodynamic therapy (PDT) is a new treatment option for peri-implantitis. The aim of this in vitro study was to analyze implant surface decontamination by means of PDT. Sixty implants were equally distributed ( $n=$ 10) into four groups and two subgroups. In group G1 there was no decontamination, while in G2 decontamination was performed with chlorhexidine. G3 (PDT-laser+dye) and G4 (laser, without dye) were divided into two subgroups each; with PDT performed for $3 \mathrm{~min}$ in G3a and G4a, and for $5 \mathrm{~min}$ in $\mathrm{G} 3 \mathrm{~b}$ and $\mathrm{G} 4 \mathrm{~b}$. After $5 \mathrm{~min}$ in contact with methylene blue dye (G3), the implants were irradiated (G3 and G4) with a low-level laser (GaAlAs, $660 \mathrm{~nm}, 30 \mathrm{~mW}$ ) for 3 or $5 \mathrm{~min}(7.2$ and $12 \mathrm{~J})$. After the dilutions, culture media were kept in an anaerobic atmosphere for 1 week, and then colony forming units were counted. There was a significant difference $(p<$ 0.001 ) between G1 and the other groups, and between G4 in
\end{abstract}

\author{
J. Marotti \\ Department of Prosthodontics and Dental Materials, \\ Medical Faculty, University Hospital RWTH Aachen, \\ Pauwelsstrasse 30, \\ 52074 Aachen, Germany \\ P. Tortamano - J. E. M. Franco - T. T. de Campos \\ Department of Prosthodontics, \\ School of Dentistry, \\ University of São Paulo, \\ Av. Prof. Lineu Prestes, 2227, \\ 05508-000 São Paulo, SP, Brazil \\ P. Tortamano \\ e-mail: tortamano@usp.br \\ J. E. M. Franco \\ e-mail: joaofranco@usp.br \\ T. T. de Campos \\ e-mail: tncampos@usp.br
}

comparison with G2 and G3. Better decontamination was obtained in $\mathrm{G} 2$ and $\mathrm{G} 3$, with no statistically significant difference between them. The results of this study suggest that photodynamic therapy can be considered an efficient method for reducing bacteria on implant surfaces, whereas laser irradiation without dye was less efficient than PDT.

Keywords Decontamination - Dental implantation · Lasers . Methylene blue $\cdot$ Photodynamic therapy $\cdot$ Titanium

\section{Introduction}

At the Sixth European Workshop on Periodontology, periimplantitis was described as an inflammatory process affecting the tissues around an osseointegrated implant, associated with suppuration, deepened pockets, and loss of supporting marginal bone [1]. Successful treatment of peri-implantitis continues to be challenging because of its complexity.

S. Cai

Department of Microbiology, Biomedical Institute,

University of São Paulo,

Av. Prof. Lineu Prestes, 2415,

05508-000 São Paulo, SP, Brazil

e-mail: silvanac@icb.usp.br

M. S. Ribeiro

Center for Lasers and Applications,

IPEN-CNEN/SP, University of São Paulo,

Av. Prof. Lineu Prestes, 2242,

05508-000 São Paulo, SP, Brazil

e-mail: marthasr@usp.br

J. Marotti $(\bowtie)$

Departamento de Prótese, Faculdade de Odontologia,

Universidade de São Paulo,

Av. Prof. Lineu Prestes, 2227,

05508-000 São Paulo, SP, Brazil

e-mail: marotti@usp.br 
During the surgical stage, the steps involved include the elimination of plaque and calculus, decontamination of the implant surface, guided tissue regeneration, and finally, maintenance of healthy conditions [2].

Effective decontamination of dental implant surfaces is one of the most difficult steps; and for this reason, several different treatments have been proposed in the literature [3-8]. Titanium implant surfaces can be cleaned by mechanical means (dental curettes, ultrasonic scalers, air-powder abrasive) and/or chemical procedures (citric acid, $\mathrm{H}_{2} \mathrm{O}_{2}$, chlorhexidine digluconate, and EDTA), usually associated with local or systemic antibiotics [9-12]. However, some of these methods can damage the surface properties of implants or promote bacterial resistance [13-15].

Recent studies have demonstrated that use of lasers can be helpful in decontamination of titanium implants. The lasers most frequently used in peri-implant care include $\mathrm{CO}_{2}$, diode, and erbium lasers, due to their hemostatic properties, selective calculus ablation and bactericidal effects. However, high power lasers can promote an undesirable increase in temperature. Another disadvantage is the high cost of equipment [16-19].

A potential alternative approach to dental implant decontamination is the association of the conventional treatment with photodynamic therapy (PDT). PDT can be described as the association of light with a suitable photosensitizer in the presence of oxygen. It is based on the principle that a photosensitizer binds to the target cells and when it is irradiated with light of specific wavelength, in the presence of oxygen, it undergoes a transition from a low-energy ground state to an excited singlet state, then singlet oxygen and other very reactive agents are produced, which are toxic to these target cells $[19,20]$.

Furthermore, it seems unlikely that resistance to PDT will develop, since its bactericidal activity is due to singlet oxygen and other reactive species such as hydroxyl radicals, which affect a range of cellular targets [21]. Many studies have demonstrated that lethal photosensitization of bacteria can be achieved in vitro without any damage to the treated titanium surfaces [20, 22-24].

Although studies have been conducted on the decontamination of dental implant surfaces by means of PDT, there is still no consensus in the literature about which PDT irradiation parameter would be best for bacterial reduction. Thus, the aim of this in vitro study was to analyze the bacterial decontamination of dental implant surfaces by means of photodynamic therapy, using two different irradiation times, in order to create conditions for a further in vivo study.

\section{Materials and methods}

This study was approved by the Research Ethics Committee of the School of Dentistry, University of São Paulo (USP), Protocol \#68/2008.

\section{Groups}

Anodized implants with rough surfaces (TiUnite, Nobel, $12 \times 4 \mathrm{~mm}$ ) were used, $n=60$, which were equally divided into two groups and two subgroups, $n=10$ for each group (Table 1). G1 and G2 were the control groups. All groups were contaminated. In G1, no decontamination was performed (negative control), while in G2 (positive control) decontamination was performed by the traditional method using a $0.12 \%$ chlorhexidine gluconate solution (PerioGard, Colgate-Palmolive). Group G3 was decontaminated by PDT (dye+laser). In group G4, laser irradiation was used, however, without dye application, in order to better evaluate the effectiveness of the use of dye on the action of PDT. Groups G3 and G4 were subdivided into two subgroups, with irradiation being performed for $3 \mathrm{~min}$ in G3a and G4a, and for $5 \mathrm{~min}$ in $\mathrm{G} 3 \mathrm{~b}$ and $\mathrm{G} 4 \mathrm{~b}$.

\section{Manipulation}

The brand new implants were carefully removed from the cases provided by the manufactor, placed on a black plate and manipulated with titanium implant plier, when necessary. All materials were sterile.

To contaminate the implants, $30 \mathrm{~mL}$ of saliva was collected from a patient previously diagnosed with periimplantitis in four implants, and the implants were kept in this saliva for $5 \mathrm{~min}$. Immediately afterwards, the decontamination procedure was performed. No drying time was allowed, so all implant surfaces were treated wet.
Table 1 Distribution of experimental and control groups

\begin{tabular}{lll}
\hline Groups & Decontamination method \\
\hline G1 (negative control) & contaminated, not decontaminated $(n=10)$ \\
G2 (positive control) & $0.12 \%$ Chlorhexidine $(n=10)$ & \\
G3 (PDT-laser+dye) & (a) Laser $3 \min (n=10)$ & (b) Laser 5 min $(n=10)$ \\
G4 (without dye, with laser) & (a) Laser $3 \min (n=10)$ & (b) Laser 5 min $(n=10)$ \\
\hline
\end{tabular}


All the steps in the methodology of this study were performed at the laboratory of the Biomedical Institute of the University of São Paulo, São Paulo, Brazil, under the same conditions $\left(22{ }^{\circ} \mathrm{C}, 60 \%\right.$ humidity, $\left.<1 \% \mathrm{CO}_{2}, 925.5 \mathrm{hPa}\right)$.

\section{Decontamination}

The implants were immersed in $3 \mathrm{~mL}$ chlorhexidine solution (G2) or in $3 \mathrm{~mL}$ of the methylene blue dye (ChimioluxHypofarma, Belo Horizonte, MG, Brazil), at a concentration of $0.01 \%$ (mass per volume) for $5 \mathrm{~min}$. The dye was used only in group G3 and after $5 \mathrm{~min}$, laser irradiation was performed with an GaAlAs low-level diode laser (Twin Laser Flex, MM Optics-São Carlos, Brazil), at a wavelength of $660 \mathrm{~nm}$. The output power of $30 \mathrm{~mW}$ was previously checked with a power meter (Power Meter 841-PE, Newport Corporation, USA) using a specific PDT fiber optic ( $\varnothing 0.5 \mathrm{~mm}, 50 \mathrm{~mm}$ length, MM Optics). Group G4 received the same treatment as G3, however, without the dye.

The irradiation time was 3 or $5 \mathrm{~min}$, according to the subgroups, and the total energy released was $7.2 \mathrm{~J}$ for the time of $3 \mathrm{~min}$, and $12 \mathrm{~J}$ for $5 \mathrm{~min}$. The fiber optic was developed especially for use in PDT. Irradiation over the entire exposed external surface of the implant was performed in contact mode. The fiber optic was positioned at one point, then in another point, and so on successively, until the irradiation time was reached (Fig. 1).

After decontamination with PDT or chlorhexidine solution, the implants were gently and slowly irrigated with two syringes, each containing $3 \mathrm{~mL}$ of sterile physiological solution. This was so that the remainders of chemical substances would not be transported to the culture medium, which would harm colony growth, particularly in the case of chlorhexidine. For the purpose of standardization, all groups were equally irrigated with sterile physiological solution, by the same calibrated operator, before microbiological analysis.

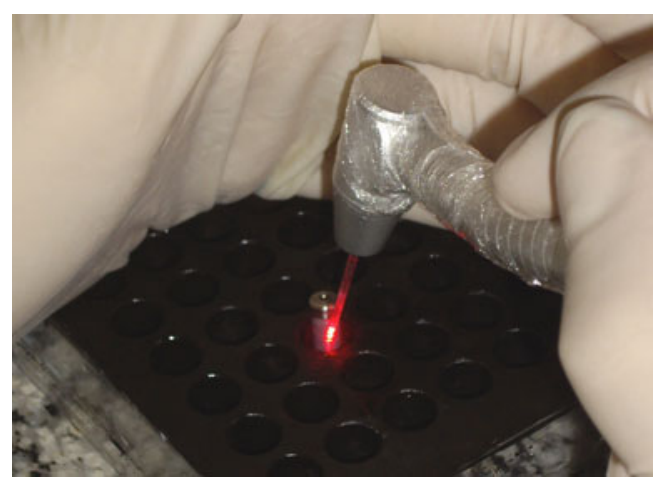

Fig. 1 Irradiation on the surface of the implant placed on the black colored prefabricated plate
Analysis of decontamination

Bacterial decontamination was quantitatively analyzed by seeding saliva in a culture medium and then counting colony forming units. This was performed using a stereoscopic microscope (Bausch \& Lomb), at $\times 10$ magnification. After the different groups were decontaminated, the implants were placed in previously sterilized microcentrifugal tubes containing peptonized water, and agitated for $30 \mathrm{~s}$, in order to detach the bacteria. Serial dilutions were then made and aliquots of $20 \mu \mathrm{L}$ were dripped on Brucella agar, according to the Miles and Misra method [25]. For each dilution, three drops were seeded. The plates were incubated at $37{ }^{\circ} \mathrm{C}$ for 7 days in an anaerobic atmosphere. The number of bacteria per milliliter was calculated according to the following formula: no. of bacteria per milliliter $=$ mean no. of colonies in the three dilutions $\times 1 /$ dilution $\times 50$.

Of the 10 implants evaluated in each group, three samples (three drops) were collected for the diluted solution of each implant. Initially, descriptive statistics were calculated; that is, mean, standard deviation, minimum, maximum, and median values of data obtained from each of the collections made for each group. Afterwards, the three collections were united and summed up by the arithmetical mean, and the summarized statistics of each group were calculated again. Table 2 shows the summarized measures of the number of bacteria per group.

All the analyses were performed with the use of the Minitab version 15.0 statistical software. The level of significance was established at $5 \%(\alpha=0.05)$, for the overall comparisons (all the groups), or $0.5 \%(\alpha=0.005)$ in the individual comparisons between two groups, using the Kruskal-Wallis test. The normality was observed by the Kolmogorov-Smirnov test $(p<0.01)$ and the difference between groups by the Mann-Whitney test.

\section{Results}

The data are presented in Fig. 2, showing the great difference in the number of bacteria found on the implants from G1, in comparison with the other groups (statistically verified by the Kolmogorov-Smirnov normality test, $p<0.010$ ). Therefore, comparison among the groups was made by the nonparametric Kruskal-Wallis test, after dispensing with the supposition of data normality.

When the Kruskal-Wallis test was applied, statistical significance was found $(p<0.001)$, indicating that there was, in fact, significant difference among groups G2, G3a, G3b, G4a, and G4b. To find out exactly which group differed from which, the Mann-Whitney test was used to make comparisons between two groups. Table 3 shows the results of the Mann-Whitney test. 
Table 2 Summarized measures of the number of bacteria $\left(\times 10^{3}\right)$ $\mathrm{mL}$, per group

$N$ number of implants evaluated per group, $S D$ standard deviation

\begin{tabular}{llrrrrr}
\hline Group & $N$ & \multicolumn{1}{l}{ Mean } & \multicolumn{1}{l}{ SD } & Minimum & Median & Maximum \\
\hline G1 & 10 & 483 & 448 & 0 & 333 & 1167 \\
G2 & 10 & 0.622 & 1.070 & 0.000 & 0.158 & 2.900 \\
G3a & 10 & 1.772 & 1.310 & 0.167 & 1.500 & 3.633 \\
G3b & 10 & 0.603 & 0.995 & 0.017 & 0.225 & 3.183 \\
G4a & 10 & 11.550 & 7.750 & 4.000 & 9.170 & 25.830 \\
G4b & 10 & 10.590 & 10.590 & 1.170 & 10.580 & 39.330 \\
\hline
\end{tabular}

As described in the statistical methodology, with the level of significance adjusted to $\alpha=0.005$ for all the multiple comparisons, it was concluded that groups G2, G3a, and G3b presented lower levels of contamination than groups G4a and G4b, and there was no significant difference among G2, G3a, and G3b. There was also no significant difference between groups $\mathrm{G} 4 \mathrm{a}$ and $\mathrm{G} 4 \mathrm{~b}$.

Figure 3 shows all the measurements obtained, indicating similarity among groups G2, G3a, and G3b, and also between groups G4a and G4b. G1 is not represented because of its great discrepancy in relation to the other groups, so a better relationship between G2, G3, and G4 can be seen.

\section{Discussion}

Although the photodynamic therapy was first used in Medicine over a 100 years ago for cancer treatment [26], only recently has antimicrobial photodynamic therapy been introduced in dentistry [20]. The benefits of laser and PDT in the many specialties of dentistry have been described in the literature, but only in the last few decades has there been increasing interest by the scientific community as regards the benefits of PDT in implant dentistry, and as a coadjuvant treatment for peri-implantitis [27-30]. Branemark's discovery of osseointegration in 1965 was extremely important to

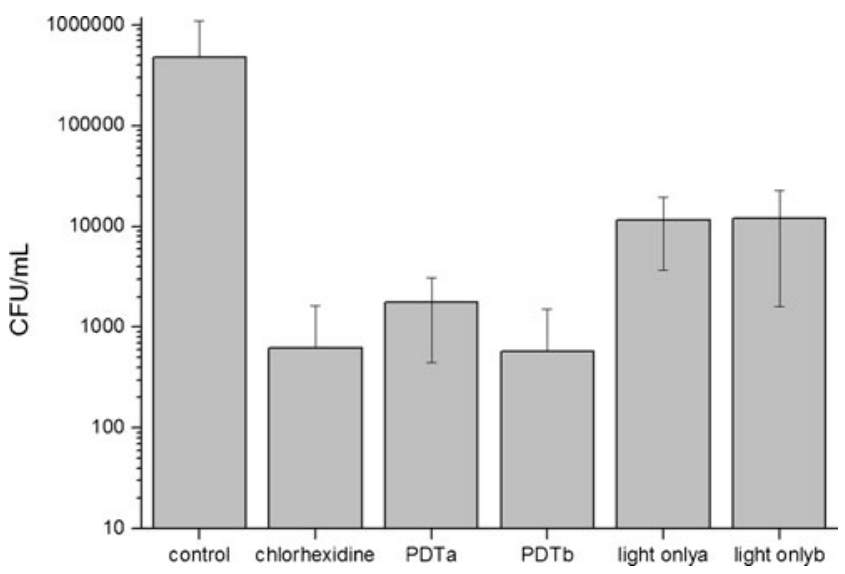

Fig. 2 Comparison of all groups after decontamination, given in $\log 10$ scale and standard deviation esthetic prosthetic restorative treatments and particularly, functional oral rehabilitation. An increasing number of patients have been rehabilitated with dental implants, and consequently, more cases of success and failure have appeared over the years. Thus, peri-implantitis has become an increasingly frequent problem in dental clinics [31].

In this study, the implants were contaminated with saliva collected from a patient previously diagnosed with periimplantitis. This patient had a history of periodontitis and he was under control treatment. Given the similarities between the diseases processes of periodontitis and periimplantitis, patients with a history of periodontal disease may be more susceptible to peri-implantitis, and this hypothesis has been supported by increasing evidence [32, 33]. In partially edentulous patients, periodontal pathogens may be transmitted by saliva from periodontally compromised teeth to newly placed implants [34]. Thus, it is important to treat periodontitis before dental implant placement [34, 35].

Different therapies have been proposed in the literature, with the aim of decontaminating the implant surface, however, none of them have been satisfactory up to now. PDT appears as another option for bacterial reduction; nevertheless, there is still no ideal protocol. Based on this doubt, the aim of the present study was to evaluate only a few of the parameters of this complex therapy.

The results obtained were in agreement with those that were expected, based on previous studies in the literature [27-30, 36, 37]. As group G1 was the negative control, in which no decontamination technique was used, it was expected to observe a great difference in the number of bacteria, in comparison with other groups. It was also expected that a larger number of bacteria would be found for Groups G4a and G4b, in comparison with the chlorhexidine (G2) and PDT (G3a and G3b) groups, as did in fact occur.

One may ask whether bacterial adherence was promoted. In fact, 5 min of implant contact with the contaminated saliva may not have been sufficient time for bacterial adherence. However, the authors were not concerned about having effective adherence, but rather to have enough time to ensure the presence of bacteria on the implant surface; which justifies the use of the term decontamination that is valid for both situations, i.e., whether microorganisms are 
Table 3 Descriptive level ( $p$ value) of the Mann-Whitney test for comparison between two groups

\begin{tabular}{lccccr}
\hline & G2 & G3a & G3b & G4a & \multicolumn{1}{c}{ G4b } \\
\hline G2 & \multicolumn{1}{c}{-} & 0.154 & 0.649 & $<0.001$ & $<0.001$ \\
G3a & 0.154 & - & 0.011 & $<0.001$ & 0.002 \\
G3b & 0.649 & 0.011 & - & $<0.001$ & $<0.001$ \\
G4a & $<0.001$ & $<0.001$ & $<0.001$ & - & 0.999 \\
G4b & $<0.001$ & 0.002 & $<0.001$ & 0.999 & - \\
\hline
\end{tabular}

attached or not. Due to the rough implant surface, indeed most of the bacterial were still attached to it, in spite of the irrigation with saline solution, which explains the great difference between $\mathrm{G1}$, in which no decontamination process was performed, and the other groups.

A great difference was noted between G1 and G4. A possible reduction in the number of bacteria in $\mathrm{G} 4$, in comparison with G1, was caused by the absorption of light by pigmented bacteria that have endogenous chromophores, which dispenses the use of an additional photosensitizing agent, thus the effects of photodynamic therapy also occurred. According to König et al. [38], bacteria such as Porphyromonas gingivalis, Prevotella intermedia, and Actinomyces odontolyticus are capable of synthesizing protoporphyrin and proto-hematoporphyrin, one of the most frequently used dyes in photodynamic therapy, which does not require the additional use of external photosensitizers. Thus, mere irradiation with red-emitting laser produces the death of these microorganisms. Through microscopic observation, the pigmented bacteria could be seen in this study, however, it cannot be affirmed which species were present, since our methodology evaluated the population of bacteria and not the specific types.
When group G4 was compared with G3, it was observed that the use of dye was important in achieving greater bacterial reduction, and this difference was statistically significant $(p<0.001)$. This result proves the real effectiveness of the association of dye with the laser light source.

There was no significant difference between G4a and $\mathrm{G} 4 \mathrm{~b}$; therefore, the irradiation time without the presence of dye did not interfere in bacterial reduction, which did not occur when G3a and G3b were compared.

In a future study, it would be interesting to increase the time of dye contact with the implant, and the irradiation time. A longer time in contact with the photosensitizer could allow more bacteria to be affected, particularly the Gramnegative type, which are more resistant to dye penetration due to the presence of an external membrane.

The results of this study complement the theory of the effectiveness of the association of laser+photosensitizer in previous studies [36, 39-42] when groups G3 and G4 are compared. In this study, while it was observed that irradiation with laser only was significantly less effective than photodynamic therapy, Chan and Lai [36] proved that laser only, or $0.01 \%$ methylene blue only had no toxicity against bacteria. The authors also stated that the dye did not convert laser energy into heat, proving that the decontamination was not due to a possible excessive increase in intracellular temperature. Dobson and Wilson [39] and Prates et al. [40] also stated that cell death was not significant in the presence of dye only or laser only.

The best results were obtained in groups G2 and G3 (chlorhexidine and PDT, respectively), differing statistically in comparison with G1 and G4 $(p<0.001)$; however, there was no statistically significant difference between $\mathrm{G} 2$ and G3. Very similar results were observed between G2 and G3b (PDT $5 \mathrm{~min}$ ). It is known that chlorhexidine has the capacity to be gradually released, and can act in periods of up to $24 \mathrm{~h}$
Fig. 3 Point graph: no of bacteria $\left(\times 10^{3}\right) / \mathrm{mL}$, per group (except G1)

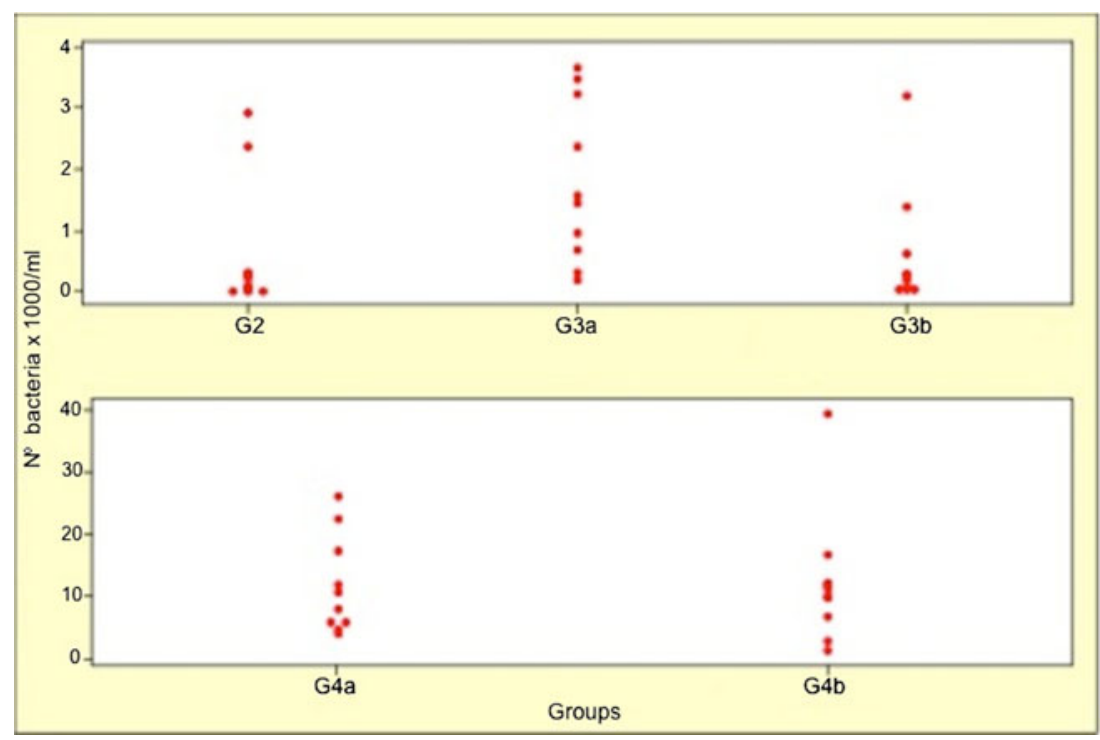


in vivo. Although the implants were abundantly irrigated with physiologic solution after decontamination with chlorhexidine, rests of the chemical substance may have remained on the implant surfaces, and consequently, have been transported into the culture medium, and continued to act against the bacteria.

Differences in the microbial analysis results with regard to the use of chlorhexidine are mainly due to the evaluation methodology and the diffusion of chlorhexidine into agar [43]. Whether or not this hypothesis is considered, the fact that G3 was statistically equal to G2, allows one to consider that photodynamic therapy would, nevertheless, be a more indicated method for decontaminating the surface of implants than irrigation with chlorhexidine solution, as it does not cause bacterial resistance and has the additional benefit of laser irradiation. The light that was not absorbed by the bacteria could be scattered and absorbed by chromophores of the adjacent peri-implant tissue, promoting biomodulation of the tissues (analgesic effect, modulation of inflammation, acceleration of the gingival and bone tissue repair processes, etc.) [44-47].

The results obtained in this study suggest that photodynamic therapy could be considered an effective method for bacterial reduction on implant surfaces and that laser irradiation alone, without the association of dye, was less efficient $(p<0.001)$ than PDT. Photodynamic therapy should, however, be considered a coadjuvant in the treatment of periimplantitis and associated with mechanical (scaling) and surgical (grafts) treatments in an endeavor to control periimplant disease.

Further studies should be conducted to test not only the laser irradiation parameters, but the photosensitizer agent, time of permanence, application mode (solution, paste, etc.), concentration, among other variables, so that an ideal protocol for the use of photodynamic therapy for the treatment of peri-implantitis may be achieved.

\section{Conclusions}

Within the parameters used in this study, it could be concluded that photodynamic therapy can be considered an efficient method for reducing bacteria on implant surfaces. Laser irradiation alone, without the association of dye, was less efficient than phtodynamic therapy.

Acknowledgments The authors would like to thanks FAPESP for the financial support (grants AP.R \#07/58045-9 and BP.MS 1 \#08/ 51876-5).

Open Access This article is distributed under the terms of the Creative Commons Attribution License which permits any use, distribution, and reproduction in any medium, provided the original author(s) and the source are credited.

\section{References}

1. Lindhe J, Meyle J (2008) Peri-implant diseases: Consensus Report of the Sixth European Workshop on Periodontology. J Clin Periodontol 35(8 Suppl):282-285. doi:10.1111/j.1600-051X.2008.01283.x

2. Esposito M, Grusovin MG, Coulthard P, Worthington HV (2008) The efficacy of interventions to treat peri-implantitis: a Cochrane systematic review of randomised controlled clinical trials. Eur J Oral Implantol 1(2):111-125

3. Ntrouka V, Hoogenkamp M, Zaura E, van der Weijden F (2011) The effect of chemotherapeutic agents on titanium-adherent biofilms. Clin Oral Implants Res 22(11):1227-1234. doi:10.1111/ j.1600-0501.2010.02085.x

4. Schwarz F, Sahm N, Iglhaut G, Becker J (2011) Impact of the method of surface debridement and decontamination on the clinical outcome following combined surgical therapy of peri-implantitis: a randomized controlled clinical study. J Clin Periodontol 38(3):276-284. doi:10.1111/j.1600-051X.2010.01690.x

5. Ungvari K, Pelsoczi IK, Kormos B, Oszko A, Rakonczay Z, Kemeny L, Radnai M, Nagy K, Fazekas A, Turzo K (2010) Effects on titanium implant surfaces of chemical agents used for the treatment of peri-implantitis. J Biomed Mater Res B Appl Biomater 94(1):222-229. doi:10.1002/jbm.b.31644

6. Quaranta A, Maida C, Scrascia A, Campus G, Quaranta M (2009) Er:Yag Laser application on titanium implant surfaces contaminated by Porphyromonas gingivalis: an histomorphometric evaluation. Minerva Stomatol 58(7-8):317-330

7. Gallardo-Moreno AM, Pacha-Olivenza MA, Fernandez-Calderon MC, Perez-Giraldo C, Bruque JM, Gonzalez-Martin ML (2010) Bactericidal behaviour of Ti6A14V surfaces after exposure to UVC light. Biomaterials 31(19):5159-5168. doi:10.1016/ j.biomaterials.2010.03.005

8. Parlar A, Bosshardt DD, Cetiner D, Schafroth D, Unsal B, Haytac C, Lang NP (2009) Effects of decontamination and implant surface characteristics on re-osseointegration following treatment of periimplantitis. Clin Oral Implants Res 20(4):391-399. doi:10.1111/ j.1600-0501.2008.01655.x

9. Faggion CM Jr, Schmitter M (2010) Using the best available evidence to support clinical decisions in implant dentistry. Int $\mathbf{J}$ Oral Maxillofac Implants 25(5):960-969

10. Norowski PA Jr, Bumgardner JD (2009) Biomaterial and antibiotic strategies for peri-implantitis: a review. J Biomed Mater Res B Appl Biomater 88(2):530-543. doi:10.1002/jbm.b.31152

11. Salvi GE, Persson GR, Heitz-Mayfield LJ, Frei M, Lang NP (2007) Adjunctive local antibiotic therapy in the treatment of peri-implantitis II: clinical and radiographic outcomes. Clin Oral Implants Res 18 (3):281-285. doi:10.1111/j.1600-0501.2007.01377.x

12. Kotsovilis S, Karoussis IK, Trianti M, Fourmousis I (2008) Therapy of peri-implantitis: a systematic review. J Clin Periodontol 35(7):621-629

13. Louropoulou A, Slot DE, Van der Weijden FA (2011) Titanium surface alterations following the use of different mechanical instruments: a systematic review. Clin Oral Implants Res. doi:10.1111/ j.1600-0501.2011.02208.x

14. Mann M, Parmar D, Walmsley AD, Lea SC (2011) Effect of plastic-covered ultrasonic scalers on titanium implant surfaces. Clin Oral Implants Res. doi:10.1111/j.1600-0501.2011.02186.x

15. Costerton JW, Montanaro L, Arciola CR (2005) Biofilm in implant infections: its production and regulation. Int J Artif Organs 28 (11):1062-1068

16. Marotti J, Geraldo-Martins VR, Bello-Silva MS, de Paula EC, Apel C, Gutknecht N (2010) Influence of etching with erbium, chromium:yttrium-scandium-gallium-garnet laser on microleakage of class V restoration. Lasers Med Sci 25(3):325-329. doi:10.1007/s10103-008-0623-6 
17. Stubinger S, Henke J, Donath K, Deppe H (2005) Bone regeneration after peri-implant care with the $\mathrm{CO} 2$ laser: a fluorescence microscopy study. Int J Oral Maxillofac Implants 20 (2):203-210

18. Marotti J, Tortamano-Neto P, Campos TT, Aranha ACC, Weingart D, Wolfart S, Haselhuhn K (2011) Recent patents of lasers in implant dentistry. Recent Patents Biomed Eng 4(2):103-105

19. Marotti J, Pigozzo MN, Nakamae EDM, Tortamano-Neto P, Laganá DC, Campos TN (2008) Terapia fotodinâmica no tratamento da periimplantite. Implant News 5(4):401-405

20. Takasaki AA, Aoki A, Mizutani K, Schwarz F, Sculean A, Wang CY, Koshy G, Romanos G, Ishikawa I, Izumi Y (2009) Application of antimicrobial photodynamic therapy in periodontal and peri-implant diseases. Periodontol 2000 51:109-140

21. Komerik N, Nakanishi H, MacRobert AJ, Henderson B, Speight P, Wilson M (2003) In vivo killing of Porphyromonas gingivalis by toluidine blue-mediated photosensitization in an animal model. Antimicrob Agents Chemother 47(3):932-940

22. Wilson M, Dobson J, Sarkar S (1993) Sensitization of periodontopathogenic bacteria to killing by light from a low-power laser. Oral Microbiol Immunol 8(3):182-187

23. Romanos GE, Gutknecht N, Dieter S, Schwarz F, Crespi R, Sculean A (2009) Laser wavelengths and oral implantology. Lasers Med Sci 24(6):961-970. doi:10.1007/s10103-009-0676-1

24. Haas R, Dortbudak O, Mensdorff-Pouilly N, Mailath G (1997) Elimination of bacteria on different implant surfaces through photosensitization and soft laser. An in vitro study. Clin Oral Implants Res 8(4):249-254

25. Miles AA, Misra SS, Irwin JO (1938) The estimation of the bactericidal power of the blood. J Hyg (Lond) 38(6):732-749

26. Allison RR, Bagnato VS, Sibata CH (2010) Future of oncologic photodynamic therapy. Future Oncol 6(6):929-940. doi:10.2217/ fon. 10.51

27. Dortbudak O, Haas R, Bernhart T, Mailath-Pokorny G (2001) Lethal photosensitization for decontamination of implant surfaces in the treatment of peri-implantitis. Clin Oral Implants Res 12 (2): $104-108$

28. Hayek RR, Araujo NS, Gioso MA, Ferreira J, Baptista-Sobrinho CA, Yamada AM, Ribeiro MS (2005) Comparative study between the effects of photodynamic therapy and conventional therapy on microbial reduction in ligature-induced peri-implantitis in dogs. $\mathrm{J}$ Periodontol 76(8):1275-1281

29. Yilmaz S, Kuru B, Kuru L, Noyan U, Argun D, Kadir T (2002) Effect of gallium arsenide diode laser on human periodontal disease: a microbiological and clinical study. Lasers Surg Med 30(1):60-66

30. Shibli JA, Martins MC, Ribeiro FS, Garcia VG, Nociti FH Jr, Marcantonio E Jr (2006) Lethal photosensitization and guided bone regeneration in treatment of peri-implantitis: an experimental study in dogs. Clin Oral Implants Res 17(3):273-281

31. Jepsen S, Ruhling A, Jepsen K, Ohlenbusch B, Albers HK (1996) Progressive peri-implantitis. Incidence and prediction of periimplant attachment loss. Clin Oral Implants Res 7(2):133-142

32. Heitz-Mayfield LJ (2008) Peri-implant diseases: diagnosis and risk indicators. J Clin Periodontol 35(8 Suppl):292-304
33. Cho-Yan Lee J, Mattheos N, Nixon KC, Ivanovski S (2012) Residual periodontal pockets are a risk indicator for peri-implantitis in patients treated for periodontitis. Clin Oral Implants Res 23(3):325-333. doi:10.1111/j.1600-0501.2011.02264.x

34. Pjetursson BE, Helbling C, Weber HP, Matuliene G, Salvi GE, Bragger U, Schmidlin K, Zwahlen M, Lang NP (2012) Periimplantitis susceptibility as it relates to periodontal therapy and supportive care. Clin Oral Implants Res. doi:10.1111/j.16000501.2012.02474.x

35. Marrone A, Lasserre J, Bercy P, Brecx MC (2012) Prevalence and risk factors for peri-implant disease in Belgian adults. Clin Oral Implants Res. doi:10.1111/j.1600-0501.2012.02476.x

36. Chan Y, Lai CH (2003) Bactericidal effects of different laser wavelengths on periodontopathic germs in photodynamic therapy. Lasers Med Sci 18(1):51-55

37. Usacheva MN, Teichert MC, Biel MA (2001) Comparison of the methylene blue and toluidine blue photobactericidal efficacy against gram-positive and gram-negative microorganisms. Lasers Surg Med 29(2):165-173

38. Konig K, Teschke M, Sigusch B, Glockmann E, Eick S, Pfister W (2000) Red light kills bacteria via photodynamic action. Cell Mol Biol (Noisy-le-grand) 46(7):1297-1303

39. Dobson J, Wilson M (1992) Sensitization of oral bacteria in biofilms to killing by light from a low-power laser. Arch Oral Biol 37 (11):883-887

40. Prates RA, Yamada AM Jr, Suzuki LC, Eiko Hashimoto MC, Cai S, Gouw-Soares S, Gomes L, Ribeiro MS (2007) Bactericidal effect of malachite green and red laser on Actinobacillus actinomycetemcomitans. J Photochem Photobiol B 86(1):70-76

41. Marotti J, Sperandio FF, Fregnani ER, Aranha ACC, de Freitas PM, Eduardo CP (2010) High-intensity laser and photodynamic therapy as a treatment for recurrent herpes labialis. Photomed Laser Surg 28(3):439-444. doi:10.1089/Pho.2009.2522

42. Marotti J, Aranha ACC, Eduardo CP, Ribeiro MS (2009) Photodynamic therapy can be effective as a treatment for herpes simplex labialis. Photomed Laser Surg 27(2):357-363. doi:10.1089/Pho.2008.2268

43. Estrela C, Bammann LL, Pimenta FC, Pecora JD (2001) Control of microorganisms in vitro by calcium hydroxide pastes. Int Endod $\mathrm{J}$ 34(5):341-345

44. Ankri R, Lubart R, Taitelbaum H (2010) Estimation of the optimal wavelengths for laser-induced wound healing. Lasers Surg Med 42 (8):760-764. doi:10.1002/1sm.20955

45. Hawkins DH, Abrahamse H (2006) The role of laser fluence in cell viability, proliferation, and membrane integrity of wounded human skin fibroblasts following helium-neon laser irradiation. Lasers Surg Med 38(1):74-83. doi:10.1002/1sm.20271

46. Sperandio FF, Simoes A, Aranha AC, Correa L, Machado O, de Sousa SC (2010) Photodynamic therapy mediated by methylene blue dye in wound healing. Photomed Laser Surg 28(5):581-587. doi:10.1089/pho.2009.2601

47. Sperandio FF, Marotti J, Aranha AC, Eduardo Cde P (2009) Photodynamic therapy for the treatment of recurrent herpes labialis: preliminary results. Gen Dent 57(4):415-419 